Volume 11, Issue 12, December 2020, pp. 311-321, Article ID: IJM_11_12_030

Available online at http://iaeme.com/Home/issue/IJM?Volume $=11 \&$ Issue $=\overline{1} 2$

Journal Impact Factor (2020): 10.1471 (Calculated by GISI) www.jifactor.com

ISSN Print: 0976-6502 and ISSN Online: 0976-6510

DOI: 10.34218/IJM.11.12.2020.030

(C) IAEME Publication

Scopus Indexed

\title{
VALUATION OF DESIRABLE AFFECTIVE DISPOSITIONS BY PRIMARY TEACHER EDUCATION LEADERS IN AMHARA REGION, ETHIOPIA
}

\author{
Melese Negash \\ Department of Early Childhood Care and Education, Faculty of Social Science and Humanity \\ Debre Tabor University, Ethiopia.
}

\begin{abstract}
Alemayehu Bishaw and Meskerem Lechissa
Department of Teacher Education and Curriculum Studies, College of Education and

Behavioral Science, Bahir Dar University, Ethiopia.
\end{abstract}

\begin{abstract}
The purpose of this study was to examine whether primary teacher education leaders in Amhara region value prospective teachers' Desirable Affective Dispositions (DADs) or not. To achieve this purpose, a mixed concurrent triangulation design was employed. Data were collected from 30 college leaders of which 27 were selected comprehensively, whereas three of them were selected purposively. Moreover, for triangulation purpose, data were collected from six teacher educators and 18 prospective teachers who were selected purposively and six prospective teachers selected using convenience sampling method. Semi-structured interview (for three leaders, six teacher educators, \& 24 prospective teachers) and questionnaire (for 27 leaders) were used to collect data. Qualitative data were analyzed using thematic analysis, whereas quantitative data were analyzed using a one-sample t-test. Both the qualitative and quantitative data disclosed that leaders are in better a state of valuing $D A D s$ of prospective teachers for different reasons that are revolving around effectiveness, professional love, professional stay, and knowledge and skill development of prospective teachers. The study shows that the valuation of DADs by leaders is an excellent opportunity to cultivate prospective teachers' $D A D$ s in the course of their training.
\end{abstract}


Valuation of Desirable Affective Dispositions by Primary Teacher Education Leaders in Amhara Region, Ethiopia

Keywords: Desirable affective disposition, leaders, Primary Teacher education, Valuation.

Cite this Article: Melese Negash, Alemayehu Bishaw and Meskerem Lechissa, Valuation of Desirable Affective Dispositions by Primary Teacher Education Leaders in Amhara Region, Ethiopia, International Journal of Management 11(12), 2020, pp. 311-321.

http://iaeme.com/Home/issue/IJM?Volume=11\&Issue=12

\section{INTRODUCTION}

Affective disposition refers to desirable and undesirable affective issues related to prospective teachers' professional, social, and personal lives. DADs are acceptable characteristic, quality, or demeanor like personality, value, attitude, belief, perception, and expectation and even social and emotional behaviors related to teaching and learning (Klein, 2008). Valuing means prizing, esteeming, appreciating, and acknowledging an object, a thing, a process , and an experience (Mohan \& Subashini, 2016).

Valuation of DADs and devaluation of Undesirable Affective Dispositions (UADs) by leaders using different strategies is a necessary precondition for DADs development and UADs weakening (Doherty, 2012). Similarly, Sherman (2016) conceived the valuation of dispositions as a key component in developing DADs. Moreover, Fonseca-Chacana (2019) pointed out that "for dispositions to be nurtured, they must be valued and perceived as pertinent to a community of practice"(p.269). Hughes (2017) added that it is mandatory to value DADs and devalue UADs. In principle, valuation of DADs should be a key agenda in the teacher preparation program (Sherman, 2016). Philosophers, researchers, students, and instructional leaders might value DADs for different reasons. For example, Prooyen (2013) valued affective dispositions of prospective teachers by believing that they are the very heart of the teacher education program. In the same way, Garcia (2014) valued DADs by perceiving them as "valuable assets with respect to both traditional school outcomes and the broader development of individuals"(p.5).

The leadership of the teaching arena including the teacher preparation program begins with words and actions that affectively uplift prospective teachers (Hughes, 2017). Pedro (2016) argued that school principals should have a proper perception about the importance of teaching disposition to be effective teachers. This implies that leaders of teacher education should value or appreciate DADs in their leadership endeavors. Zenkert (2013) asserted that teacher education administrators valued prospective teacher's dispositions, but they believed that dispositions are not as important as knowledge and skill. Similarly, Taylor (2014) pointed out that as DADs are valued by leaders and affective dimensions of teaching were integrated into the mission and values of teacher training colleges by leaders. This is because designing mission statements and identifying the values of an institution are primarily the roles of leaders. Moreover, Karges-Bone and Griffin (2009) contended that leaders could serve as sources of dispositions such as compassion, fairness, curiosity, respect, and integrity when they are interacting with prospective teachers by valuing these affective qualities. Leaders might not value all DADs equally. For instance, Stimpson (2010) found out that the four most valued teachers' dispositions by educational institution leaders are treating students fairly, encouraging and motivating students, conveying enthusiasm toward teaching, and hold positive regard for others. On the other hand, Frederiksen (2010) pointed out that it is a relational disposition that is highly prized by faculty administrators. Nevertheless, educational institution leaders might not be found at the same footing in valuing different prospective teachers' DADs for several reasons. 
The aforementioned claims would seem to imply that leaders might have their own contribution in developing DADs by valuing the perceived importance of prospective teachers' DADs using different valuing strategies. In the ideal context, we expect leaders to value DADs and devalue UADs when they interact with teacher educators and prospective teachers. They are also expected to establish an official institutional system that values DADs.

\subsection{National context}

Cognizant of the DAD importance, different Ethiopian educational national documents such as Education and Training Policy (Federal Democratic Republic Government of Ethiopia [FDRGE],1994), Education Sector Development Program-II (MOE, 2002), Teacher Education System Overhaul(MOE, 2003), Professional Standard for Ethiopian School Teachers (MOE, 2012a) , and Curriculum Framework for Primary Pre-service Teacher Education (CFPPTE) (MOE,2012b) have acknowledged DADs. The commitments on the part of MOE in acknowledging prospective teachers' DADs in its different national documents call forth all primary Teacher Education Colleges (TEC) leaders in Ethiopia including the colleges in Amhara National Regional State (ANRS), which is one of the ten regions in Ethiopia to value prospective teachers' DADs. However, existing literature indicated that Ethiopian primary schools teachers are poorly motivated in their professional endeavor (MOE, 2017); primary school extension prospective teachers demonstrated different UADs (Eskeziyaw ,Molla, \& Mamuye 2019); Ethiopian teachers had not been morally cultivated during their course of training (Dewo, 2011); Ethiopian teacher education program would not seem in a position to prepare teachers who could help children as early as possible towards a more spiritual, ethical, and morally sound direction (Lechissa, 2014). Such underdevelopment of DADs on the part of prospective teachers might be the function of DAD devaluation culture reflected in TECs in general and leaders in particular. The existence of such reality in TECs is a challenge as a nation and might result in a sever value crisis in the contemporary Ethiopian society which casts its evil shadow in all walks of our life in general and education system in particular. This challenging reality could be curved if leaders value DADs and establish an official institutional DAD valuation system.

However, as far as researcher knowledge is concerned, whether leaders value DADs or not and to what extent they appreciate the perceived importance of DADs are issues that were not addressed via research in ANRS primary TECs. This initiated the researcher to conduct the present study on these issues because addressing the issues is paramount.

\subsection{Objectives of the study}

Two objectives were identified to guide the study.

- to crosscheck whether leaders believed that DADs are important for prospective teachers or not

- to examine the extent of leaders' perceived practice in valuing DADs.

\subsection{Research leading questions}

- Do leaders believe that DADs are important? Why?

- To what extent do leaders value DADs?

\section{METHODOLOGY}

\subsection{Sampling and sample size}

The study was conducted in three of the ten primary TECs found in Amhara region. The study employed a mixed research approach with concurrent triangulation design. The total samples 
of the study were 30 leaders, six teacher educators, and 24 prospective teachers. Twentyseven of leaders were selected comprehensively to fill a questionnaire, but three leaders, six teacher educators and 18 prospective teachers were selected purposively for interview purpose. Moreover, six prospective teachers who were selected conveniently participated in the interview.

\subsection{Data-gathering tools}

A close-ended questionnaire, a semi-structured interview, and FGD were used to collect data. The questionnaire was a five-point Likert scale adapted from Varol (2011) and Zenkert (2013). It consisted of 30 items, which were classified into five subscales coined as care, intellect, character, practice of teaching, and professionalism. The scale range from 1(strongly disagree) to 5(strongly agree).

\subsection{Data presentation, analysis, and interpretation}

Qualitative data were presented using texts and analyzed using thematic qualitative content analysis. Zenkert (2013)DADs classification framework was used in classifying DADs. Quantitative data were analyzed using descriptive statistics (mean and standard deviation) and inferential statistics (one-sample t-test) at $\mathrm{P}<0.05$ level of significance using SPSS version 23 .

\subsection{Trustworthiness and credibility}

To maximize the trustworthiness of measuring instruments, the researcher's advisors and different professionals commented on the first draft. The comments forwarded by all professionals were considered in revising and finalizing the data gathering tools. After incorporating the comments, the instruments were piloted at one of the TECs found in Amhara region. Cronbach alpha reliability coefficients of the DADs valuation scaled questionnaire during the pilot study were 0.82, whereas for the final study it was 0.91 . According to George and Mallery( 2003), the coefficient values for the pilot and final study were good and excellent, respectively.

\section{RESULT OF THE STUDY}

\subsection{Leaders' belief about the importance of DADs}

As disclosed by the qualitative data, leader were found holding the same belief about the importance of DADs for prospective teachers' future professional, social, and personal lives by giving different justifications. Results are presented using pseudonyms for sample colleges and respondents for the sake of confidentiality.

All leaders believed that DADs are more important than knowledge and pedagogical skills. For instance, DX3 from college X pointed out that:

The importance of DADs is unquestionable because prospective teachers who have DADs such as accepting the profession and having a positive attitude towards it can easily develop their pedagogical skills and subject matter knowledge. It is impossible for a prospective teacher to develop knowledge and pedagogical skill in the absence of DADs.

In the same way, DY3 from college Y, believed that desirable dispositions identified by the government or prospective teachers brought with when joining the teaching profession are "very important and even more important than subject matter knowledge and pedagogical skills in making prospective teachers more effective and efficient in their future professional life." As he was a Civic and Ethical education teacher, he was also asked that is it your specialization that would make you to value DADs? Nevertheless, he strongly asserted that it is "my nature or personality, but not my specialization that made me highly value DADs.

Similarly, DZ3 from college Z claimed that: 
DADs are more important than knowledge and skills because it is possible to develop knowledge and pedagogical skills through additional effort. If an individual possessed DADs like love, commitment, and considerateness, it would be easy to develop subject matter knowledge and pedagogical skills.

The data from leader interviewees signify that they believe DADs are more important than subject matter knowledge and pedagogical skills by giving different justifications. The reasons they gave were logical and targeted at subthemes like effectiveness, professional love, staying in the profession and gateway for knowledge and skill development of prospective teachers. The overall results suggest that leaders in the sample TECs believed that DADs are important for prospective teachers' future professional, social, and personal success for different reasons.

\subsection{Leaders' DAD valuing practices extent}

The qualitative data revealed that leaders had their own different experiences in valuing prospective teachers' DADs. Their actual experiences are presented as follows.

Regarding the practice of valuing prospective teachers' DADs, DX3 from college $\mathrm{X}$ reported his experience as follow:

Personally, I had the experiences of valuing students who are demonstrating DADs. Practically, I gave money to different students when they are displaying DADs because I value affective quality more than cognitive quality. I valued an ethical student who had 2.00 GPA more than the unethical student who had 4.00 GPA. However, as a leader, I did not establish an institutional official valuation system of DADs. It is a high GPA scoring students who are officially recognized, rewarded, and promoted through public media, but ethical and morally sound students have never been appreciated. Similarly, in our college, we did the same thing because yearly we reward those who scored better GPA during graduation by expending a lot, but not those who are highly ethical and morally sound. Therefore, as a leader, my overall contribution in establishing an official institutional valuation system for DADs is nonexistent.

\section{DY3 from college $Y$ asserted that}

As leaders, we never establish DADs valuation system because of the national culture and absence of a policy that forced us to do so. We fail to appreciate prospective teachers who are ethical and morally sound, rather we give recognition for students who are unethical and immoral. Whatever ethical and morally sound our students are, we leaders never acknowledge them. However, I had a personal commitment to value DADs using different valuation strategies. For example, I gave recognition for a student who submitted a necklace to the college that he got in the college campus by posting his name on notice board. I also introduced him at the flag ceremony as a good role model in demonstrating honesty.

\section{DZ3 from college $Z$ stated that}

There is no official and institutional valuing system for DADs in our college because of lack of attention, commitment, and awareness, orientation problem, and the education system we passed through. However, personally, I appreciated students who demonstrated DADS informally, but never appreciate them ceremonially.

The self-report data of leaders were triangulated with the data obtained from teacher educators and prospective teachers. For example, TE1 suggested that leaders as a team fail to take any action or to value DADs regularly. Nevertheless, PT1 stated that some leaders showed individual commitment to value affective qualities because "once a day, one student got 360 birrs and gave it to the college. Consequently, one of the deans promoted this honesty virtue at flag ceremony and communicated through notice board by posting his name." PT1 added that leaders punish UADs and fired unethical prospective teachers. For example, one 
prospective teacher who were engaged in sexual harassment and quarreled with teacher educators was fired. Likewise, FGD discussants reported that "some leaders had the experience in valuing DADs because they always avail themselves at flag ceremony and during this session, they tried to appreciate DADs and discourage UADs."

TE3 from college Y mentioned that there is no organized valuation and rewarding system of DADs established by leaders as a team at college level. However, leaders at a personal level valued DADs incidentally. To cite one, "the name of a student was posted on notice boards when he submitted a necklace to the office he obtained somewhere in the college compound" (TE3). PT3 also asserted that not all deans are contributing equally to value prospective teachers' DADs. Similarly, FGD discussants asserted that leaders as a team did not establish an official system to value DADs as the result of negligence, lacking attention, commitment, experience, and skills, and absence of accountability system.

TE5 reported that leaders in their college never establish an official system to value DADs .For instance, there is no affective quality valuation system during graduation at the college or department level like that of cognitive quality (TE5). Likewise, TE6 stated that there is no official valuing system for DADs at college and department level because they lack commitment, make themselves busy by routines activities, and give priority for GPA. Similarly, PT5 and PT6 asserted that leaders did not establish DADs valuation system because of lacking leadership skill and attention. FGD discussants reported that no weekly, monthly, semester wise, and annual valuation system of DADs on the part of our college leader. However, GD13 reported that the dean of our college appreciates DADs and he is a good role model, but the two vice deans are negligent of the issue. The overall qualitative data disclosed that most leaders have personal commitment, but not leadership team spirit in valuing DADs by establishing an official valuation system for different reasons. The data also disclosed that all leaders had a personal commitment, but not leadership team spirit in valuing DADs by establishing an official valuation system for different reasons. The reasons could be framed as personal intrapersonal, and extra-personal.

Table 1. Valuation of prospective teachers' DADs by leaders

\begin{tabular}{|c|c|c|c|c|c|c|c|c|}
\hline DAD related themes & $\mathbf{N}$ & $\mathbf{O M}$ & $\mathbf{E M}$ & MD & SD & t-value & df & $\begin{array}{c}\text { Sig. (2- } \\
\text { tailed) }\end{array}$ \\
\hline Care & 27 & 31.82 & 24 & 7.82 & 4.68 & 8.67 & 26 & $0.000^{*}$ \\
\hline Character & 27 & 12.00 & 9 & 3.00 & 2.47 & 6.32 & 26 & $0.000^{*}$ \\
\hline Intellect & 27 & 27.63 & 21 & 6.63 & 3.69 & 9.33 & 26 & $0.000^{*}$ \\
\hline Practice of teaching & 27 & 31.15 & 24 & 7.15 & 4.94 & 7.51 & 26 & $0.000^{*}$ \\
\hline Professionalism & 27 & 14.63 & 12 & 3.63 & 2.47 & 7.64 & 26 & $0.000^{*}$ \\
\hline Overall & 27 & 118.22 & 90 & 28.22 & 15.51 & 9.46 & 26 & $0.000^{*}$ \\
\hline
\end{tabular}

Significant at $\mathrm{p}<0.05^{*}$

An attempt was made to check the perceived practice of leaders in valuing prospective teachers' DADs using a 30-item overall valuation scale with a five subscales using a onesample t-test. The result revealed that the perceived DAD valuing practice observed mean of subscales care, character, intellect, practice of teaching , and professionalism $(31.82,12.00,27.63,31.15, \& 14.63)$ respectively were greater than their respective expected means $(24,9,21,24, \& 12)$. Moreover, the analysis revealed that the observed mean of DAD valuing perceived practice of the overall scale (118.22) was greater than the expected mean 
(90). The results show that the difference between the observed and expected mean scores is significant at $\mathrm{p}<0.05$. This implies that leaders have a better level of DAD valuing perceived practice for the overall and specific (care, character, intellect, practice of teaching, \& professionalism related) DADs of prospective teachers.

\section{DISCUSSION OF RESULTS}

\subsection{BELIEFS OF LEADERS ABOUT THE IMPORTANCE OF DADS}

Prospective teachers' DADs development is the function of the extent to which they are valued (Doherty, 2012; Fonseca-Chacana, 2019). Ideally, we expect leaders to value DADs. Regarding this assumption, the qualitative findings revealed that all leader participants believed that DADs are as important as knowledge and pedagogical skills in making prospective teachers effective and efficient. The valuing of DADs by leaders is in harmony with the existing literature (Hughes, 2017; Stimpson, 2010; Varol, 2011; Zenkert, 2013). For instance, Stimpson claimed that "dispositions are as important as or even more important than the subject matter and teaching skills taught in teacher education institutions" (p.22).

Participants expressed their belief about the importance of DADs by giving different justifications. To cite a few, as DADs are vital to act ethically and morally, individuals are affective oriented, and the success story of our life is the function of affective qualities, DY3 believed that DADs are very important for prospective teachers. Likewise, DZ3 claimed that DADs are important to have a constructive and productive mind.

The valuation of DADs by leaders implies that they have similar and deeper perception about the significance of DADs for prospective teachers to be effective and efficient in their future professional, social, and personal lives. It also indicates they have better awareness about DADs because it is natural that we never value something that we did not know. Besides, the rationales given by leaders for their belief about the importance of DADs have different implications. For example, the justifications given by DY3 seem to imply that the process of creating ethical and morally sound citizens is the function of cultivating prospective teachers' DADs because if prospective teachers possessed DADs, they would positively influence the affective dispositional qualities of a generation. One of the rationales forwarded by DY3 also reminds us that the professional, social, and personal success or failure story of an individual is the outcome of his/her affective dispositional status because human beings are affective in their nature. Consistent with this claim, Smith (2009) (as cited in Wilkerson, 2017) argued that "human beings are primarily affective beings before they are cognitive beings"(P.36). Likewise, the rationale given by DZ3 reminds us that TECs, which invest a lot in cultivating subject matter knowledge and pedagogical skills by neglecting DADs are colleges which produce a destructive mind, but not a productive mind. The reasons behind leaders' belief about the worthiness of DADs for prospective teachers were related to effectiveness, professional stay, professional loving, and knowledge and skills development.

The positive perception leaders hold about the importance of DADs for student teachers is an excellent opportunity to launch an affective revolution in TECs and to help prospective teachers to develop DADs and weaken their UADs. Supporting this argument, FonsecaChacana (2019) underscored that the valuation of DADs is a mandatory precondition for their development. Leaders' perception about the worthiness of DADs for prospective teachers by might be attributed to their professional and socio-cultural background. Therefore, the professional and socio-cultural backgrounds are common denominators that enable leaders to believe that DADs are more important than knowledge and pedagogical skills for prospective teachers. 
Valuation of Desirable Affective Dispositions by Primary Teacher Education Leaders in Amhara Region, Ethiopia

\subsection{Leaders' DADs valuing practice extent}

Good professional leaders of teacher education are expected to appreciate prospective teachers when they demonstrate DADs. Regarding this claim, one of the leader interviewee (DX3) shared his experience as such: "personally, I gave money for different students when they are displaying DADs because I value affective quality more than cognitive quality." This qualitative finding was congruent with the one-sample $\mathrm{t}$-test because the test disclosed that leaders have better level of DAD valuing perceived practice in relation to care, character, intellect, practice of teaching, and professionalism related specific DADs and overall DADs. This result is congruent with (Hughes, 2017; Pedro, 2016; Zenkert, 2013). Teacher educators and prospective teachers shared these findings too. These findings suggest that at a personal level, leaders have the commitment and practically value DADs informally and formally. If professionally and strategically institutionalized and systematized, this personal commitment of leaders in giving recognition for DADs is really promising, interesting, exemplary, and fertile ground to prospective teachers' DAD development and UAD weakening.

On the other hand, all leaders in their qualitative response confirmed that they are not at equal footing in their actual practice of valuing DADs and their practice is not in the form of leadership team spirit. Teacher educators and prospective teachers also shared these findings. Leader interviewees expressed the reality as such: "as a leader my overall contribution in establishing official institutional valuing system for DADs is nonexistent" (DX3); "whatever ethical and morally sounding our students are, we as leaders never acknowledged them" (DY3).

The overall finding shows that there is no leadership team spirit among leaders in valuing DADs. The result also shows that there is no official established affective quality acknowledging system at a college or department level established by leaders like that of cognitive competence. This social reality might be a great challenge in nurturing DADs in TECs. Moreover, unless DADs valuation is institutionalized and systematized, the personal commitment of leaders would not result in significant DAD development out come. The variation of giving recognition for prospective teachers by leaders when they demonstrate DADs might be the function of their perception of reality. The reasons mentioned for the absence of leadership team spirit were themed as intrapersonal, interpersonal , and extrapersonal, which again could be themed as societal and hidden curriculum related factors. The results indicated that there are congruence and incongruence among some qualitative and quantitative results regarding DADs valuing practice of the three parties. The congruence confirms the credibility of the findings. On the other hand, the incongruence reminds further research to be conducted on the area.

The overall qualitative results suggest that leaders had a positive belief about the importance of DADs. In the same way, the overall quantitative result indicates that leaders have a better state of DAD valuing perceived practice. Such a state of primary teacher education leaders leads to arguing that as sources of hidden curriculum messages, they seem positively contribute to develop DADs by holding a belief that DADs are important and giving actual recognition for DADs. This signifies that the hidden curriculum experiences in TECs regarding DADs valuation are in the right position to have a positive contribution to the development of prospective teachers' DADs. 


\section{CONCLUSIONS AND RECOMMENDATIONS}

The qualitative and quantitative findings of this study lead to declare that leaders are valuing the overall DADs and specific care character, intellect, practice of teaching, and professionalism related DADs. They perceived DADs as important by forwarding different logical, acceptable, and professional reasons, which are related to effectiveness, professional stay professional loving, and knowledge and skills development. However, leaders are not at equal footing in their actual valuation of DADs for several reasons, which were themed as intrapersonal, interpersonal and extra-personal related factors.

The appreciation of DADs by primary teacher education leaders based on their personal commitment is promising that should be further strengthened. TEC leaders should establish an official DAD valuation system like that of the cognitive dimension. More specifically, leaders should have a team spirit in valuing DADs. As a whole, the valuation of DADs should be cultured in TECs. Leaders should take the lion share in valuing DADs in all walks of their life in their college. The results also remind Ethiopian MOE and Amhara region's education bureau officials to be informed about the positive experiences of teacher education leaders in valuing DADs of prospective teachers.

\section{ACKNOWLEDGEMENT}

I would like to express my heartfelt thanks to my advisors Alemayehu Bishaw (Professor) and who helped me to finalize my research work by providing unreserved professional comments and supports from the beginning to the end. I would like also to express my thanks to my advisors my ex-advisor Meskerem Lechissa(PhD) who helped me to finalize my research work by providing unreserved professional comments and supports from the beginning to the mid of the project. Moreover, my acknowledgment goes to Bahir Dar and Debere Tabor University those financially supported this doctoral project. Last, but not least, I would like to thank all those who supported me in my doctoral project journey.

\section{REFERENCES}

[1] Buchanan, M. M. (1971). Preparing teachers to be persons. The Phi Delta Kappan, 52(10), 614-617.

[2] Dewo, T. (2011). Inculcation of moral values for improving quality education. Journal of Quality and Relevant Education and Training (JQRET), 1(1), 43-55.

[3] Doherty,B (2012). Disposition development: A neglected voice for the pursuit of excellence among college students.

[4] Eskeziyaw, Y., Molla, A., \& Mamuye, K. (2019). Bedebre Berihan memhrane timihirt koleg bemataw yesiltna merhagibir yehuletgna amet beamist yememariya kifloch yemisletinu selitagnoch yemitayewun yesinemigibar chigir endet meqiref enichilalne [How can we avoid immoral behaviours of five section second year evening trainees. Annual Journal of Educational Reseacrh, 2, 85-103.

[5] Federal Demaocratic Republic Gevernment of Ethiopia. (1994). Education and training policy. ST. George printing Press.

[6] Fonseca-Chacana, J. (2019). Making teacher dispositions explicit: A participatory approach. Teaching and Teacher Education, 77, 266-276.doi: https://doi.org/10.1016/j.tate.2018.10.018 
Valuation of Desirable Affective Dispositions by Primary Teacher Education Leaders in Amhara Region, Ethiopia

[7] Frederiksen, H. (2010). Assessing dispositions in pre-service teachers: Does setting or experience affect dispositions? A mixed-methods study(Unpublished doctoral dissertation). Colorado State University.

[8] Garcia, E. (2014). The need to address noncognitive skills in the education policy. Economic Policy Institute Briefing Paper \#386, 1-36.

[9] George, D., \& Mallery, P. (2003). SPSS for windows step by step: A simple guide and reference.

[10] Hughes, M. (2017). Elevated dispositions for teacher leadership. Servant Leadership: Theory \& Practice, 4(2), 85-96.

[11] Karges-Bone, L., \& Griffin, M. (2009). Do they have the right dispositions? Teacher education in the new conceptual age. SRATE Journal, 18(2), 27-33.

[12] Klein, S. R. (2008). The use of dispositions in preservice Art teacher evaluation. Studies in Art Education, 49(4), 375-380.doi: https://doi.org/10.1080/00393541.2008.11518749

[13] Lechissa, M. (2014). Utopianism and anti-Utopianism in the ways older Ethiopian children construct their national identity and implications for social studies Education(Unpublished doctoral dissertation). University of Cincinnati.

[14] Ministry OF Education. (2012). Curriculum framework for primary pre-service teacher education.Unpublished

[15] Ministry OF Education. (2002). Education sector development program -II.Retrived from https://cse.google.com/cse?q=Needs+assessment+result+to+launch+MED+in+educational + sci ence $\% \mathrm{E} 2 \% 80 \% \mathrm{AF} \% 3 \mathrm{~A}+\mathrm{Teaching}+\mathrm{of}+$ Mathematics $+\% 26+\mathrm{M} \& \mathrm{sa}=$ Search\&ie $=\mathrm{UTF}-$ $8 \& \mathrm{cx}=$ partner\%2Dpub\%2D1780369399756513:4997575038\#\%9C

[16] Ministry OF Education. (2003). Teacher education system overhaul (TESO)Handbook . Retrived from https://cse.google.com/cse?q=Needs+assessment+result +to+launch+MED + in+educational + science $\%$ E2\% $80 \%$ AF\%3A + Teaching + of + Mathematics $+\% 26+$ M\&sa $=$ Searc h\&ie $=$ UTF-8\&cx=partner\%2Dpub\%2D1780369399756513:4997575038\#\%9C

[17] Ministry OF Education. (2017). Ethiopian education development roadmap: An integrated executive summary. In policy draft document. Retrived from https://cse.google.com/cse? $\mathrm{q}=$ Needs + assessment + result + to + launch $+\mathrm{MED}+$ in + educational + science $\% \mathrm{E} 2 \% 80 \% \mathrm{AF} \% 3 \mathrm{~A}+\mathrm{T}$ eaching + of + Mathematics $+\% 26+$ M\&sa $=$ Search \&ie $=$ UTF- $8 \& c x=$ partner $\%$ 2Dpub\%2D1780369399756513:4997575038\#\%9C

[18] Mohan, A., \& Subashini, A. E. (2016). Role of teachers in inculcating values among students. Value Education through Teacher Education, 1(2), 23-28.

[19] Pedro, R. (2016). Exploring teacher disposition toward diverse learners within public elementary school(Unpublished doctoral dissertation). Southern New Hemispher University.

[20] Prooyen, T. L. VAN. (2013). Examination of a dispositional system in a teacher:Amixed methods case study(Unpublished doctoral dissertaion). Illinois State University.

[21] Sherman, S. (2016). Moral dispositions in teacher education: Making them matter. Teacher Education Quarterly, Fall 2006, 41-57. doi: https://doi.org/10.4018/978-1-4666-6280-3.ch012 
[22] Stimpson, M. E. (2010). The intersection of positive Psychology and teachers 'dispositional fitness : A delphi study(Unpublished doctoral disseration). Loyola University.

[23] Taylor, L. D. (2014). The affective domain in nursing education: Educators' perspectives(Unpublished doctoral dissertaion). The University of Wisconsin-Milwaukee.

[24] Varol, V. (2011). Teacher educators 'perceptions about teacher dispositions(Unpublished doctoral dissertaion). Florida State University.

[25] Wilkerson, Joshua B., T. M. . (2017). Cultivating mathematical affections: developing a productive disposition through engagement in service-learning (Unpublished doctoral dissertaion).Texas State University.

[26] Zenkert, A. J, J. (2013). Defining, operationalizing, developing, and assessing candidate dispositions in teacher education (Unpublished doctoral dissertaion). Boise State University. 